\title{
The syndrome of inappropriate antidiuresis after vaccination against COVID-19: case report
}

\author{
Gregor Lindner and Basil Ryser ${ }^{*}$ (10
}

\begin{abstract}
Background: The Syndrome of Inappropriate Antidiuresis (SIADH) has been described to be associated with a multitude of conditions and medications, including the severe acute respiratory syndrome coronavirus 2 . We describe the case of a patient with newly diagnosed and symptomatic SIADH after receiving the second COVID-19 vaccination not explained otherwise.
\end{abstract}

Case presentation: A 79-year-old male person was admitted to the emergency department due to a worsening of his general health state expressed by weakness, fatigue and anorexia. Vital signs and clinical findings were normal, in particular the patient was considered to be euvolemic. Laboratory investigations revealed a serum sodium of $117 \mathrm{mmol} / \mathrm{L}$, a serum osmolality of $241 \mathrm{mosm} / \mathrm{kg}$ and a urea of $1.2 \mathrm{mmol} / \mathrm{L}$ with creatinine within normal range. Urine chemistry showed a urine osmolality of $412 \mathrm{mosm} / \mathrm{kg}$ and urine sodium of $110 \mathrm{mmol} / \mathrm{L}$. TSH, C-reactive protein, and basal cortisol levels were normal. Under therapy with balanced crystalloid fluids, hyponatremia worsened and in absence of diuretic medications, diagnosis of SIADH was made. Since fluid restriction was not sufficiently effective, oral urea was administered. Under this therapy regimen hyponatremia resolved.

Conclusions: Local as well as systemic reactions have been described for the new mRNA-based vaccines including pain and fever. Therefore, it is imaginable that the vaccine might trigger SIADH in some patients.

Keywords: SIADH, Hyponatremia, COVID-19 vaccination, Case report

\section{Background}

The Syndrome of Inappropriate Antidiuresis (SIADH) is characterized by a low serum sodium, reduced serum osmolality, relatively high urine osmolality and urine sodium together with a clinically euvolemic patient in absence of diuretic medication [1]. SIADH has been described to be associated with a multitude of conditions and medications with diseases of the lung being quite prominent [1]. Only recently, SIADH was also described in patients infected with the Severe Acute Respiratory Syndrome Coronavirus 2 (SARS-CoV-2) $[2,3]$. To this date, intensive vaccination programs have started worldwide in order to fight the pandemic [4]. In our country

*Correspondence: basil.ryser@icloud.com

Department of Internal and Emergency Medicine, Buergerspital

Solothurn, Schoengruenstrasse 42, 4500 Solothurn, Switzerland at this time, only Spikevax (mRNA-1273, Moderna) and Comirnaty (BNT162b2, Pfizer-BioNtech) were approved by our local drug administration. They both contain messenger ribonucleic acid (mRNA) coding for spikeproteins of the SARS-CoV-2 virus. The mRNA is transported into hosting cells in lipid nanoparticles, where the proteins are synthesized and presented on the cell membrane [5,6]. This leads to an immune reaction against the presented antigens, which results in a T- and B-Cell activation and consecutively in a humoral and cellular immune response $[5,6]$. The most common side effect is a solicited local reaction $[5,6]$. Furthermore, common side effects reach from fever, headache and fatigue to lymphadenopathy, myalgia, arthralgia, nausea/vomiting and chills. Unfortunately, there are also rare cases of anaphylactic shock after receiving either of the mentioned vaccines. Recently, a case series of Myocarditis and 
Pericarditis associated with COVID-19 vaccination was published [7]. Since vaccination programs started, a lot of case reports were published describing a multitude of pathologies possibly related to the vaccination. They are reaching from thyreoiditis, over Guillan-Barré syndrome, to stroke-mimics and uveitis, to only mention a few [8$11]$. We describe the first case of a patient with newly diagnosed and symptomatic SIADH after receiving the second COVID-19 vaccination not explained otherwise.

\section{Case presentation}

A 79-year-old male person was admitted to the emergency department on March 06th 2021 due to a worsening of his general health state expressed by weakness, fatigue and anorexia. The patients' previous medical history was remarkable mainly for an ischemic cerebrovascular insult in 2019, which probably occurred on basis of microangiopathic disease. Moreover, gastritis and gastroesophageal reflux disease was known. The patient was on a regular medication of clopidogrel $75 \mathrm{mg}$ as well as pantoprazole $40 \mathrm{mg}$ once daily, respectively. non-steroidal anti-inflammatory drug (NSAID) use was denied.

Clinical examination on admission showed a patient in slightly reduced general state of health, normotensive blood pressure values, a heart rate of $66 / \mathrm{min}$, a peripheral oxygen saturation of $97 \%$ on ambient air as well as a temperature of $37^{\circ} \mathrm{C}$. The patient did not have any peripheral edema and was considered to be euvolemic.

Laboratory investigation revealed a serum sodium of $117 \mathrm{mmol} / \mathrm{L}$ on admission, potassium of $4.3 \mathrm{mmol} / \mathrm{L}$ and a serum osmolality of $241 \mathrm{mosm} / \mathrm{kg}$ with a serum creatinine of $67 \mu \mathrm{mol} / \mathrm{L}$ and a urea of $1.2 \mathrm{mmol} / \mathrm{L}$. TSH and $\mathrm{C}$-reactive protein levels were normal. Hyponatremia

Table 1 Serum and urine chemistry results on admission

\begin{tabular}{lll}
\hline Parameter & Reference range & Case \\
\hline Sodium & $136-145 \mathrm{mmol} / \mathrm{L}$ & 117 \\
Potassium & $3.6-5.1 \mathrm{mmol} / \mathrm{L}$ & 4.3 \\
Calcium & $2.20-2.60 \mathrm{mmol} / \mathrm{L}$ & 2.20 \\
Phosphate & $0.74-1.52 \mathrm{mmol} / \mathrm{L}$ & 0.93 \\
Osmolality & $270-295 \mathrm{mosm} / \mathrm{kg}$ & 241 \\
Glucose & $4.6-6.1 \mathrm{mmol} / \mathrm{L}$ & 4.8 \\
Creatinine & $49-90 \mu \mathrm{mol} / \mathrm{L}$ & 67 \\
Urea & $3.5-7.2 \mathrm{mmol} / \mathrm{L}$ & 1.2 \\
C-reactive protein & $<5.1 \mathrm{mg} / \mathrm{L}$ & 3.3 \\
TSH & $0.35-4.94 \mathrm{mU} / \mathrm{L}$ & 3.19 \\
Basal Cortisol & $101-536 \mathrm{nmol} / \mathrm{L}$ & 101 \\
Urine & & \\
Sodium & $\mathrm{mmol} / \mathrm{L}$ & 110 \\
Creatinine & $\mu \mathrm{mol} / \mathrm{L}$ & 9.592 \\
Osmolality & $\mathrm{mosm} / \mathrm{kg}$ & 412 \\
\hline
\end{tabular}

was confirmed in arterial blood gas analysis, to exclude pseudo-hyponatremia. The patient was administered intravenous crystalloid solutions and admitted to the medical ward. In order to determine the etiology of hyponatremia a urine chemistry was ordered: Urine osmolality was $412 \mathrm{mosm} / \mathrm{kg}$ and urine sodium $110 \mathrm{mmol} / \mathrm{L}$. In order to rule out adrenal insufficiency a basal cortisol was ordered for the next day, which was in the normal range $(101 \mathrm{nmol} / \mathrm{l})$. On admission laboratory results are given in Table 1 . The patients' serum sodium further declined to $116 \mathrm{mmol} / \mathrm{L}$ with the intravenous crystalloid solution. Moreover, respiratory multiplex PCR (Influenza A, Influenza B, SARS-CoV2, RSV A and B) was negative.

On basis of a clinically euvolemic patient, absence of diuretic medication, high urine osmolality and urine sodium of $110 \mathrm{mmol} / \mathrm{L}$ together with a relevant hypoosmolar hyponatremia the diagnosis of SIADH was made. Fluid restriction at $1.000 \mathrm{ml} /$ day was started, which led to a slight increase in serum sodium. In order to assess for a triggering factor for the SIADH a detailed history was obtained excluding any medications taken in addition to the previously mentioned ones. Moreover, computed tomography of the chest was performed since the patient was a former smoker. However, no signs for malignancy, inflammation or infection were found. Pantoprazole was taken already for a long time and clopidogrel is not known to be associated with SIADH. Taken together, it was supposed that the potential trigger for the SIADH might be the second vaccination against COVID-19 (mRNA-1273, Moderna) the patient received on February 26th 2021 (the first vaccination was injected 14 days earlier).

Since fluid restriction was only moderately effective, oral urea was administered first at $30 \mathrm{~g} /$ day and later at $45 \mathrm{~g} /$ day. Under this therapeutic regimen, the serum sodium concentration increased to $133 \mathrm{mmol} / \mathrm{L}$ on March 12th 2021. The patient always reported to tolerate interventions very well, in particular also the bitter taste of urea. The initially expressed weakness and fatigue improved markedly and the patient was discharged the same day with appointments in order to perform a ureafree interval in 7-14 days post-discharge for evaluation of potential resolving of SIADH. March 17th a control of serum sodium yielded a value of $139 \mathrm{mmol} / \mathrm{L}$ and urea therapy was paused in order to assess for resolvement of SIADH.

\section{Discussion and conclusions}

We are reporting the first case of SIADH in the context of previous vaccination against COVID-19 in a 79-year-old patient, who presented with marked hyponatremia. 
Hyponatremia has been described to be a common occurrence in various lung diseases and is associated with adverse outcome of patients [12]. Hyponatremia in the context of SIADH has also been linked to several conditions of the lungs including COVID-19 [1-3]. During the last months vaccination programs against COVID19 started internationally, administering immunizations to an increasing number of people. Local as well as systemic reactions have been described for the new mRNA based vaccines including pain, local erythema, headache, fatigue and fevers [13]. Therefore, it is imaginable that the vaccine per se might trigger SIADH in some patients, since SARS-CoV-2 infections are also associated with SIADH [2]. However, pathophysiology leading to SIADH remains unclear. In the present case, no alternative triggering agent could be identified, leaving the previous vaccination as a plausible cause. The main limitation of this case report is that causality of SIADH can only be presumed but not proofed. Further research is necessary to show if there is an actual correlation between mRNA SARS-CoV-2 vaccinations and SIADH, and to understand the underlying pathophysiology. Awareness of the potential side effect is crucial in physicians caring for patients suffering from prolonged symptoms after COVID-19 vaccination in order to identify and treat these patients. In conclusion, when hyponatremia is occurring after mRNA COVID-19 vaccination, treating physicians should be aware of possible SIADH.

\section{Abbreviations}

SIADH: Syndrome of Inappropriate Antidiuresis; SARS-CoV-2: Severe Acute Respiratory Syndrome Coronavirus 2; NSAID: Non-steroidal anti-inflammatory drugs; mRNA: Messenger ribonucleic acid.

\section{Acknowledgements}

Not applicable.

\section{Authors' contributions}

$G L, B R$ were involved in the diagnosis and treatment of the patient. GL and $B R$ performed the manuscript draft. GL, BR critically revised the manuscript draft. Both authors read and approved the final manuscript.

\section{Funding}

None to report.

\section{Availability of data and materials}

Data sharing is not applicable to this article as no datasets were generated or analyzed during the current case report.

\section{Consent for publication}

Written informed consent was obtained from the patient for publication of this case report and any accompanying images.

\section{Competing interests}

The authors declare that they have no competing interests.

Received: 8 April 2021 Accepted: 14 September 2021

Published online: 25 September 2021

References

1. Ellison DH, Berl T. Clinical practice. The syndrome of inappropriate antidiuresis. N Engl J Med. 2007;356(20):2064-72. https://doi.org/10.1056/ NEJMcp066837 (PMID: 17507705)

2. Ravioli S, Niebuhr N, Ruchti C, Pluess E, Stoeckli T, Lindner G. The syndrome of inappropriate antidiuresis in COVID-19 pneumonia: report of two cases. Clin Kidney J. 2020;13(3):461-2.

3. Uddin Chowdhury MR, Akter KS, Moula MM, Kabir MA, Bhuiyan SI, Das BC. COVID-19 presented with syndrome of inappropriate ADH secretion(SIADH): a case report from Bangladesh. Respir Med Case Rep. 2020;31:101290.

4. Goralnick E, Kaufmann C, Gawande AA. Mass-vaccination sites - an essential innovation to curb the Covid-19 pandemic. N Engl J Med. 2021. https://doi.org/10.1056/NEJMp2102535.

5. CHMP. Assessment report: COVID-19 Vaccine Moderna Common. 2021;31(31 March):9-153.

6. CHMP. Assessment report COVID-19 Vaccine Comirnaty. EMA/707383/2020 Corr $^{*}$. 2021;31(February):1-140.

7. Diaz GA, Parsons GT, Gering SK, Meier AR, Hutchinson IV, Robicsek A. Myocarditis and pericarditis after vaccination for COVID-19. JAMA. 2021. https://doi.org/10.1001/jama.2021.13443 (PMID: 34347001).

8. Leber HM, Sant'Ana L, da Silva NR, Raio MC, Mazzeo TJ, Endo CM, Nascimento H, de Souza CE. Acute thyroiditis and bilateral optic neuritis following SARS-CoV-2 vaccination with coronavac: a case report. Ocul Immunol Inflamm. 2021.

9. McKean N, Chircop C. Guillain-Barré syndrome after COVID-19 vaccination. BMJ Case Rep. 2021;14(7): e244125. https://doi.org/10.1136/bcr2021-244125 (PMID: 34330729).

10. Rattanawong W, Akaratanawat W, Tepmongkol S, Chutinet A, Tantivatana J, Suwanwela NC. Acute prolonged motor aura resembling ischemic stroke after COVID - 19 vaccination (CoronaVac): the first case report. J Headache Pain. 2021;22(1):93.

11. ElSheikh RH, Haseeb A, Eleiwa TK, Elhusseiny AM. Acute Uveitis following COVID-19 vaccination. Ocul Immunol Inflamm. 2021;11:1-3. https://doi. org/10.1080/09273948.2021.1962917 (PMID: 34379565).

12. Ravioli S, Gygli R, Funk GC, Exadaktylos A, Lindner G. Prevalence and impact on outcome of sodium and potassium disorders in patients with community-acquired pneumonia: a retrospective analysis. Eur J Intern Med. 2021;85:63-7.

13. Baden LR, El Sahly HM, Essink B, Kotloff K, Frey S, Novak R. Efficacy and safety of the mRNA-1273 SARS-CoV-2 Vaccine. N Engl J Med. 2021;384(5):403-16.

\section{Publisher's Note}

Springer Nature remains neutral with regard to jurisdictional claims in published maps and institutional affiliations.

\section{Declarations}

